Article

\title{
The 5E Model of Environmental Engagement: Bringing Sustainability Change to Higher Education through Positive Psychology
}

\author{
Cathy Macharis ${ }^{1, *(\mathbb{D}) \text { and Dorit Kerret }}{ }^{2}$ (D) \\ 1 MOBI Research Group, Vrije Universiteit Brussel, 1050 Brussels, Belgium \\ 2 The Department of Public Policy, Tel-Aviv University, Tel Aviv 6997801, Israel; doritk@post.tau.ac.il \\ * Correspondence: Cathy.Macharis@vub.be; Tel.: +32-(0)2-614-83-03
}

Received: 20 November 2018; Accepted: 27 December 2018; Published: 5 January 2019

check for updates

\begin{abstract}
What is the role of universities in advancing sustainability? This paper delineates a unique program for promoting sustainability that was applied in Vrije Universiteit Brussels (VUB). The unique characteristics of the program are described in light of the positive sustainability framework. The five components of the program are designed to promote sustainable behavior of participants, through promoting goal-oriented hope: setting a goal; believing that one can successfully achieve the chosen goal (agency thinking); viewing the potential paths for achieving the goal (pathway thinking); and trusting other members of society to follow the same desired goal (social trust). The five components of the program are designed to jointly raise all the elements of hope. It starts with goal setting (estimate), which is aimed at evaluating the impact of the university on the physical environment. Secondly, the entire community of the university should be engaged in achieving the desired goal. The third component of the method is education about the potential options and actions for achieving the designed goal. Then, enabling the achievement of the goal takes place (meaning making it easy). Lastly, participants should be encouraged to pursue the goal by positive rewarding.
\end{abstract}

Keywords: higher education; education for sustainability; positive psychology; environmental behavior; positive sustainability

\section{Introduction}

How can universities contribute to a path toward sustainability? What kind of role can universities assume in creating a sustainable behavioral change toward a more sustainable lifestyle? This paper delineates a specific program based on extensive theoretical grounds that was applied at Vrije Universiteit Brussel (VUB) for inducing and sustaining environmental behavior. This pilot program should hopefully inspire other institutions to pursue similar models.

The initiative discussed in this paper was created following the increased public awareness that global society needs to transform in a sustainable manner. According to the Brundtland report, sustainable development is essentially a process of change that incorporates, without compromise, the needs of future generations in the decision-making process [1]. However, changing behavior is a complex matter [2]. If you want to create a real sustainable change, providing knowledge is not enough [3]. Emotions and the physical environment (the context) should also be taken into account $[4,5]$. Heath and Heath [6] provide a clear metaphor for illustrating this point: if you want to let an elephant change its path, you will have to talk to the rider (our brain) but also to the elephant (our emotions) and make the new path much easier and attractive than the old one. The metaphor is clear: we might truly know it is better to recycle or to go by bike to our work, but to change our behavior and sustain the change, it needs to be emotionally rewarding and easy to follow. If recycling is very complicated 
or if the cycling is very dangerous, the chances of pursuing these goals is significantly reduced [5]. Although the literature significantly contributed to the understanding of inaction regarding climate change [7], little is known about the ways to confront these reasons and processes to encourage action through various institutional settings and interventions.

Higher education has the important potential for enabling such a process of change [8,9], as universities play a quadrate role as a social change agent (Figure 1). Universities have the societal mandate to increase levels of understanding through research and teaching future decision-makers and citizens, but they also have an important role through their outreach and operations [10]. It is clear that higher education has an important role in bringing students up to date with the ever-evolving concepts of sustainable thinking [11]. However, again, knowledge alone is not enough to create behavioral change. Many institutions follow the whole-institution approach [12]. Following this approach, universities implement sustainability in all their operations. Apart from implementing sustainability in teaching and promoting state-of-the-art research, universities may also serve as a role model through managing their own campuses in a state-of-the-art manner and initiating outreach through educating the general public through various initiatives [12]. While many initiatives of the whole-university approach occur around the globe [13], none of these initiatives systematically focus on promoting their environmental behavior through the lens of a positive sustainability model.

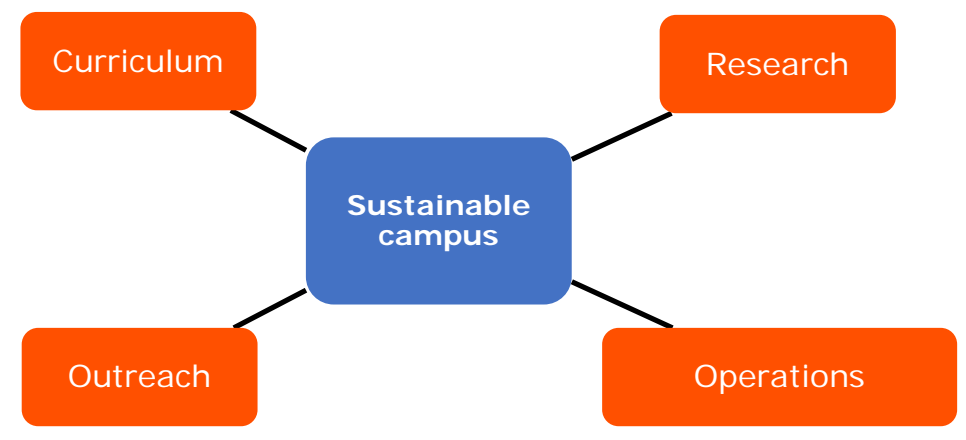

Figure 1. The entire institutional approach.

The innovative positive sustainability model showed that the same processes may increase both environmental behavior and subjective well-being [14] and were specifically applied to the educational process in schools [15]. This paper suggests a practical implementation of this model in the context of higher education. As an illustration of the approach, we detail an intervention process that contains the main elements that may induce both environmental behavioral change and simultaneously increase the subjective well-being of all campus users. As our model suggests cognitive goal-oriented hope as a primary variable affecting both the dependent variables, our focus on the intervention was based on the processes of building hope. This paper elaborates on a specific program that was designed following the milestones of the positive sustainability approach and was applied at VUB. The next section provides the theoretical grounds for constructing the intervention program, followed by a detailed description of the model. The paper concludes with discussing the model and its future implications.

\section{Theoretical Grounds of the Five E Model}

Following the positive sustainability model, environmental goal-oriented hope [14], which is the basis of the intervention described in this paper, includes four elements. Firstly, as suggested by its title, a goal should be set. The second element includes the belief that one can successfully achieve the chosen goal (agency thinking). The third element suggests viewing the potential paths for achieving the goal (pathway thinking), and the last element is trusting other members of society to follow the same desired goal (social trust). The intervention that is discussed in the subsequent sections includes all these elements. 
The specific intervention described in this paper follows the positive sustainability model, as it created a process that was aimed at raising goal-oriented environmental hope. The program described in this paper includes five elements that have the theoretical potential to induce all the elements of environmental goal-oriented hope (Figure 2). This new 5E model can be seen as an operationalization of the positive sustainability model. It allows having a toolkit to create the environmental hope setting.

Impact of positive sustainability $=$ Estimate $\times$ Engage $\times$ Educate $\times$ Enable $\times$ Encourage

Figure 2. Elements of the positive sustainable change program (Macharis, 2018).

The program starts with goal setting (estimate). To evaluate the extent of the specific impact of the university on the physical environment and consequently set compatible goals, a comprehensive estimation should be performed. Secondly, the entire community of the university should be engaged in achieving the desired goal. The third component of the method is education about the potential options for achieving the designed goal, including the potential actions that they can take themselves. Then, enabling the achievement of the goal is also a part of the plan. This means that the path to attain this goal should be made easy. Lastly, participants should be encouraged to pursue the goal that was set by rewarding them in a positive way.

All the stages of the program are designed to jointly raise all the elements of hope. Setting the specific goals is done following the "estimate" stage, which is elaborated on in the next section. The belief in the capacity to influence and induce change (agency thinking) is facilitated through all four stages, which is elaborated on below. In addition, different paths toward achieving the goal are designed, implemented, and demonstrated through the "educate", "enable", and "encourage" stages, as elaborated on in the next section.

Arguably, the most imminent component of the "five E" approach is enabling a participatory approach to induce collaboration among all the campus actors, thus building the trust that is a part of the environmental hope model. Helferty and Clarke [16] indicated in their review that, in most cases, the sustainability initiatives in universities in which the students are participating are organized by staff or faculty members. The benefit of the role played by the staff and faculty is that they can change the institution from within, which is a powerful middle-out transformative force [17]. While student initiatives are scarce, both approaches to change that are led by top-down (staff) or bottom-up (students) are not without many pitfalls [17]. Hence, the best option to achieve higher engagement by students is the organization of a so-called shared power relationship [16]. Astin and Astin [18] advised creating an institutional climate for transformative leadership on campus that facilitates individual and collective efforts to address climate change. The role of students is also important because students provide new energy, enthusiasm, and extra political power/pressure to implement the initiatives [17]. Successful student-led campaigns can be a stimulation for other new initiatives and create extra pressure to change university policy and operations [17]. However, commitment and engagement cannot be forced. People are more likely to engage in climate change actions if the approach is voluntary [19]. Group activities and peer-led programs are more successful in encouraging the long-term modification of behavior than information campaigns [20]. The approach described in the subsequent sections takes such an approach of engaging all the actors of VUB.

\section{The Five Elements of Positive Sustainability Intervention for Environmental Behavioral Change-The Case Study of VUB}

\subsection{Estimate}

The first stage of the program was setting the goals. To make a change, it is important to know the size of the problem. This knowledge enables a better view of what is happening and determines if a change (action) is necessary. Typically, what can be done for a university is to estimate its carbon footprint. 
For VUB (Vrije Universiteit Brussel), this was performed in 2017 according to the Bilan Carbone ${ }^{\circledR}$ methodology of the French Association Bilan Carbone with $\mathrm{CO}_{2}$ emission values adapted to a Belgian context. The carbon footprint consists of the on-site direct emissions of an organization versus the indirect emissions outside the location of the organization. These indirect emissions can be caused by energy consumption both on site and elsewhere. As a consequence, according to the International Organization for Standardization (ISO) standard, the carbon footprint is subdivided into three scopes.

Scope 1 (direct greenhouse gas (GHG) emissions) consists of all the direct greenhouse gas emissions on site or by the cars owned by an organization or company. This involves the fuel consumption for heating, machinery and mobility, as well as possible leaks of cooling gases from cooling installations.

Scope 2 (electricity indirect GHG emissions) consists of indirect greenhouse gas emissions as a result of the direct consumption of purchased electricity on site. These indirect emissions are the emissions from electricity power plants.

Finally, Scope 3 (other indirect GHG emissions) contains all other indirect emissions related to the production of purchased products (goods and services), the processing of waste, commuting, transport, and business travel (excluding company cars, which are included in Scope 1). Based on data from many organizations that conducted comprehensive assessments of their Scope 3 emissions, it is evident that Scope 3 GHG are by far the largest component of most organizations' carbon footprint.

The carbon footprint of VUB is 31,871 tons $\mathrm{CO}_{2} \mathrm{e}$ (See Figure 3). The global warming potential is used to calculate the equivalent amount of carbon dioxide required to heat the earth equally over the next 100 years. For example, one ton of methane is equivalent to 34 tons of $\mathrm{CO}_{2}$. Each greenhouse gas can be translated into tons of $\mathrm{CO}_{2}$-equivalents $\left(\mathrm{CO}_{2} \mathrm{e}\right)$. As a comparison, this is the equivalent of driving 125 million $\mathrm{km}$ with a car. This amount also corresponds to the total yearly carbon footprint of almost 1600 average people in Belgium $(0.014 \%$ of the total Belgian carbon footprint). It requires 1.3 million trees to absorb this amount of $\mathrm{CO}_{2}$ within one year.

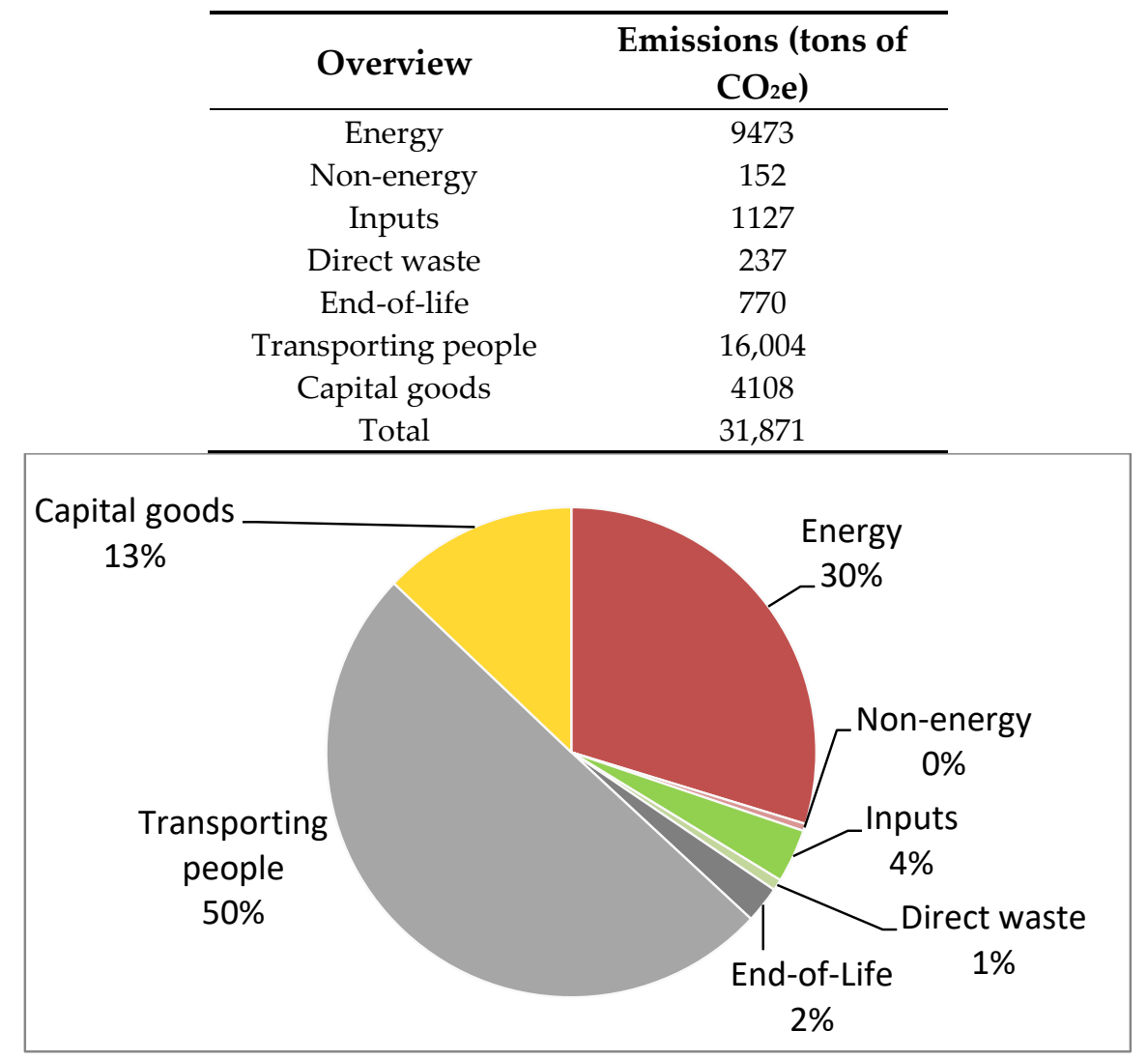

Figure 3. Bilan Carbone ${ }^{\circledR} \mathrm{CO}_{2} \mathrm{e}$ emissions in \% per category for Vrije Universiteit Brussels (VUB). 
What became very clear from this estimation is that transport and energy were the most important categories to look at. Within transport, part of the contribution is due to the flights that academic personnel and students are performing, and part is due to home-work travel. For the latter, it became clear that VUB personnel were not using private transportation for work commuting; however, they often lived quite far from Brussels, which increased their carbon footprint, even though they commuted by train [21]. The goal was set to make the university $\mathrm{CO}_{2}$ free by 2030 .

\subsection{Engage}

As described above, knowing is not enough. People need to feel engaged before they feel they also own the problem. At VUB, we experimented with several ways to engage the academic community. The first was a large university-wide campaign targeted at students. Here, we worked more on the curriculum part of the whole-institution approach, but we managed to engage all stakeholders from all four parts of the system (see Figure 1). The second way was to organize a sustainability forum in which we asked the community which actions had to be taken. At that moment, we did not yet have the results of the carbon footprint analysis, which would have been a very good start to the discussion. However, the main targets, such as energy and mobility, were already clearly in scope. For this engagement action, all four parts of the whole-institution approach were in scope and all stakeholders groups were involved.

\subsubsection{We Are Paris: A University-Wide Campaign on Climate Change}

\section{Campaign Set-Up}

The We Are Paris campaign (end of 2015) was the result of a wish to establish a participative project in which the larger university community could participate and engage themselves, preferably with a strong influence on and initiative from the students. It sought synergy with the Climate Conference in Paris from the end of November until the beginning of December 2015 (see the logo of the campaign in Figure 4). The initiative was a university-wide initiative open to all students of all faculties, and even students from other Belgian universities joined. Through the promotion campaign at the beginning of the academic year, we were able to attract 130 subscribers on the website. At the kick-off meeting and presentation, a total of 76 students were either present or indicated a strong interest. Sixty-five of them eventually volunteered to participate in the project and joined one of the editorial teams. After the start, three additional students signed up. Of the 68 students at the start, 44 stayed through the end and published one or more editorial pieces on the We Are Paris website.

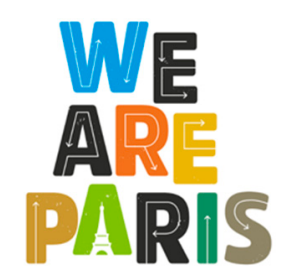

Figure 4. We are Paris campaign logo.

To be able to set up the We Are Paris participative project, we needed to construct a framework in which the students could actively participate in an independent way. We decided to work with editorial teams in which the students were responsible for the different tasks inherent to such an environment. Apart from writing articles about climate-change-related topics, they also had to produce videos and think about social media. The platform they used to publish their editorial pieces was a Wordpress blogsite specially constructed around the project and a Facebook page: https://www.facebook.com/weareparis2015/. 
Ten Topics, Ten Teams

Because "climate change" in itself is too broad a topic and we wanted to avoid possible overlaps in content once the students started working in independent teams, we narrowed the concept down using ten different angles based on relevant issues. The resulting ten topic fields were agriculture and food, climate change, energy, households and social commitment, industrial production, nature conservation, trade, services and globalization, transportation, urban planning and urbanization, and water management. These topic fields were then used to build the editorial teams. Participants of the project could state a preference for one or more of these topics when signing up to actively take part in the project. Of course, some of the topics were in higher demand than others, but we were able to put together teams of a minimum of five people without disregarding the indicated inclinations of the students.

Once the teams were assembled, the students could start working. The assignment was to research and explore stories, people, projects, companies, studies, etc. that set a positive example in fighting climate change today and to report on them. For each team, one duo of students was expected to go on the road and make a video report on a project, company, or person that had an interesting story to tell within the team's topic field. The technical composition of this video was outsourced to a professional team that joined the students on their trip. To go to these places, the students were encouraged to use eco-friendly means of transport.

Support

To support the students content-wise, ten VUB professors with an academic background in one of the topics were approached to commit to the project. Their primary task was to help students find suitable content, to bring them into contact with interesting people in their network, and to serve as a sounding board whenever the students needed feedback. Apart from that, they also had the opportunity to contribute to the blogsite themselves with an editorial piece.

In addition to the supporting professors, a team of professional experts was assembled to provide the teams with guidelines on the editorial work: copy, video, and social media. Each team started with a training in these fields so that they knew what was expected and how they could go about the task. After that, it was up to students to start working as an editorial team with the support and help of the assigned professor and the team of experts. The students needed to set up a publishing calendar and assign tasks among the members.

The teams had an allocated meeting room on campus at their disposal where they could have meetings or work whenever they wanted to. The experts were also present at fixed times to follow up on the progress of the group and to support the students where necessary.

The initiative was a great way to engage the students on the topic, and it also engaged many academics and people from the administration. It was the beginning of change for the whole university. The next step was to move toward concrete actions, which we did in the sustainability forum.

\subsubsection{Engaging Stakeholders with the Interview Method (Sustainability Forum 2016)}

"One of the steps to move forward in the transition toward sustainable higher education is to develop innovative and creative initiatives to engage the university (including external stakeholders) in discussions about the role higher education can play in the transition toward sustainable development and in developing an institutional understanding, culture, vision, mission, and planning on sustainability in higher education." [22].

Engaging the university through collective reflection and discussion is a rather unconventional practice in academia, which, above all, has a strong interest in individual knowledge production and merit. Collective participatory processes risk being perceived as time-consuming and counterproductive, creating a false sense of policy participation. Being aware of these pitfalls, 
the sustainability steering committee of the university nevertheless took the chance and invited the academic community to an interactive workshop: Sustainability Forum VUB 2030.

Approximately fifty people with a different profile participated in the forum, i.e., bachelor and master students, administrative staff of all levels, and academic staff from various disciplines. The participants were personally invited and selected due to their particular knowledge and position at the university. However, how is it possible to gather the best ideas and take all opinions into account during just one afternoon? The "interview method", in which each participant is invited to share his/her opinion about each topic from his/her perspective, was shown to be a very fruitful model. In Figure 5 the different steps of this method are explained. This methodology was previously used in a large program, Flanders in Action, and was known to be a very useful method to include everyone's opinion at the same time and be very effective in terms of time use [23].

Interview method: how does it work?

Step 0: Formulate four ambitious statements beforehand and match them with a chosen color. For example, "Which measures could VUB take to boost the sustainability of its (1) energy consumption $=$ red, $(2)$ mobility $=$ green, $(3)$ life style $=$ yellow, and (4) outreach $=$ blue".

Step 1: composing the groups

Compose small groups of four people, each of them belonging to a different color/group (a group with a red, a green, a yellow, and a blue member). Try to build in as much diversity within the groups as possible.

Step 2: my answer (5 min)

Every participant reflects for five minutes on his/her "own" statement, i.e., the statement corresponding to his/her color. For example, a participant in the red group is asked to reflect on the following statement for $5 \mathrm{~min}$ : "Which measures could VUB take to boost the sustainability of its energy consumption?" All participants write down their answers.

Step 3: three interviews (30 min)

The interviewing of the other members of the group can begin. The yellow member of the group asks the green member what he/she thinks about the yellow statement. The interview takes $5 \mathrm{~min}$ and the answer is written down. It is important that the interviewer does not start to discuss with the person who he/she is interviewing, but just writes down the ideas of the other person. Then, vice versa, the green member asks the yellow member what he/she thinks about the green statement. Again, the interview takes maximum 5 min and notes are made. At the same time, the red and the blue members interview each other.

This process is repeated three times until everyone is interviewed by the three others, e.g., the yellow member interviews and writes down the answers of his/her three other colleagues about the yellow statement and the yellow member is interviewed by his/her colleagues about the three other statements.

Step 4: conclusion per color group

Participants in each color group sit down and discuss the answers to the statements they collect. What are the actions to take? For which actions is there support and for which actions do they see too many barriers? Optionally, a moderator of the discussion and a rapporteur are designated.

Step 5: plenary presentation of outcomes and round-up

The conclusions of each group are presented in a plenary session (by the rapporteur). Extra input, corrections, or time for questions and answers (Q\&A) is possible.

Figure 5. The interview method: the different steps to take.

The draft output of the forum was summarized into 15 actions in different domains. Via an online survey, 108 stakeholders with different profiles demanded the prioritization of these actions for the mid-long term (see Figure 6). By engaging stakeholders a second time in the planning of sustainability 
actions and by broadening the group, we reached several goals; the participant base was further broadened, and they were given the possibility to also take a lead role for certain actions. The board of directors of the university, on the other hand, received a clear overview of the sustainability issues that the stakeholders urged the university to act on. The "bureaucratic distance" [17] was bridged between the top-down and bottom-up levels.

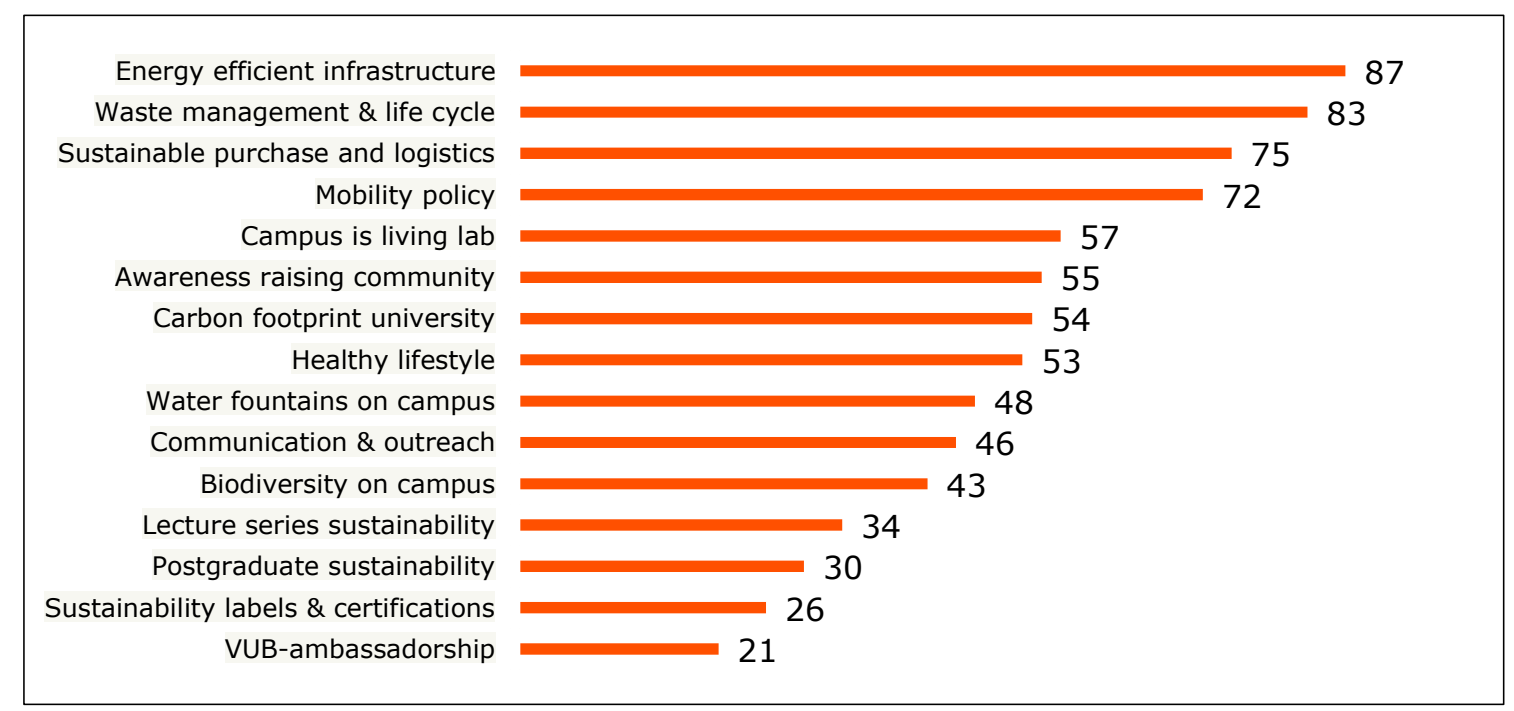

Figure 6. Fifteen sustainability actions and the corresponding percentage of participants judging this action as having the highest priority for VUB (in \%).

In a follow-up question, we asked respondents what kind of actions they wanted to support (see Figure 7). Forty-six respondents answered this question, of which $41 \%$ were students or Doctor of Philosophy $(\mathrm{PhD})$ students, $31 \%$ were people from the administration, and $28 \%$ were academic personnel.

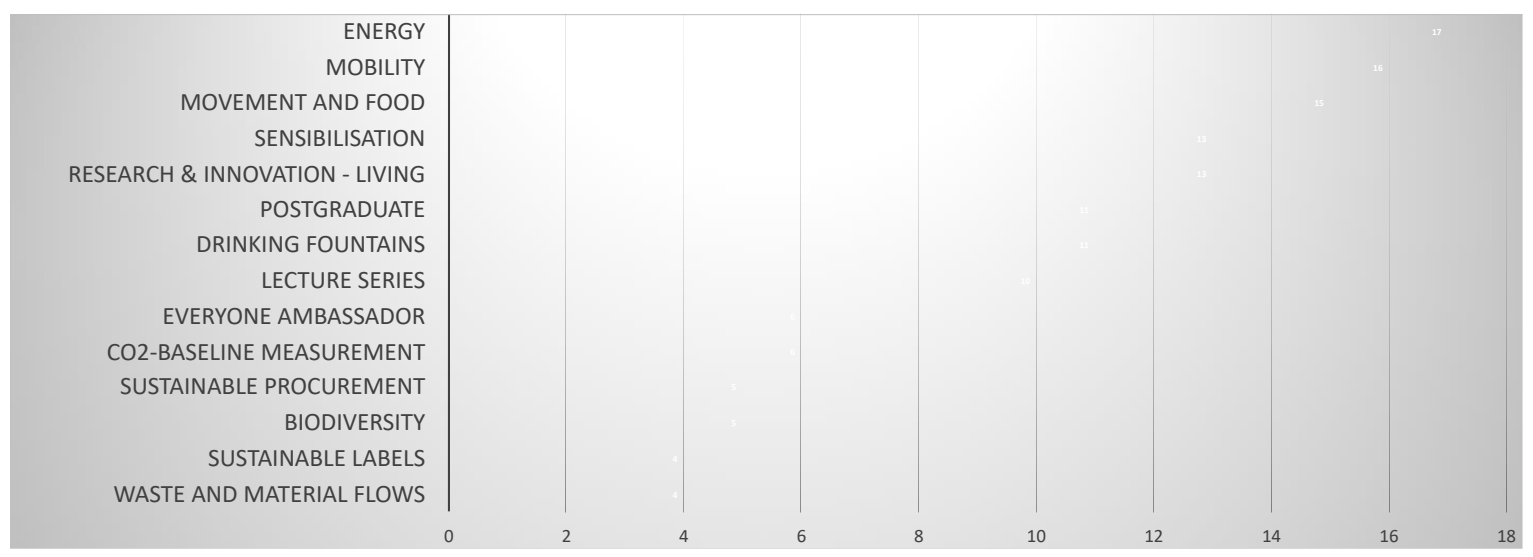

Figure 7. Support for actions (amount of respondents willing to support the action).

These two participatory approaches to engage with the university community led to an increased awareness on sustainability and a wish to continue working on specific domains. The results of the sustainability forum, indicating the highest-priority domains, were taken as a lead for the activities of the sustainability core team.

\subsection{Educate}

If people are engaged, they still need to be empowered or educated on what they can do and how they can do it. Within the university, much knowledge on sustainable behavior is available but 
often not in a practical, usable, and interdisciplinary way. We brought all this knowledge together in a four-day intense course called Sustainability Bootcamp (see the program in Figure 8). The lectures were given by both academic and operational experts from different disciplines. Getting inspired for innovation and meeting peers in an open atmosphere at the campus in Brussels was the ultimate goal of this bootcamp. The combination of academic lectures pointing out the latest knowledge in the field together with professionals sharing their experiences was a unique and enriching concept. The Sustainability Bootcamp in April 2018 hosted 40 enthusiastic participants, 18 academic experts, and eight guest professionals in an open debate setting at the Vrije Universiteit Brussel. During four intense days, a wide range of topics and various perspectives offered a broad view on sustainability. This interesting gathering and multidisciplinary environment resulted in eye-opening lectures, sharp discussions, and state-of-the-art training in sustainability.
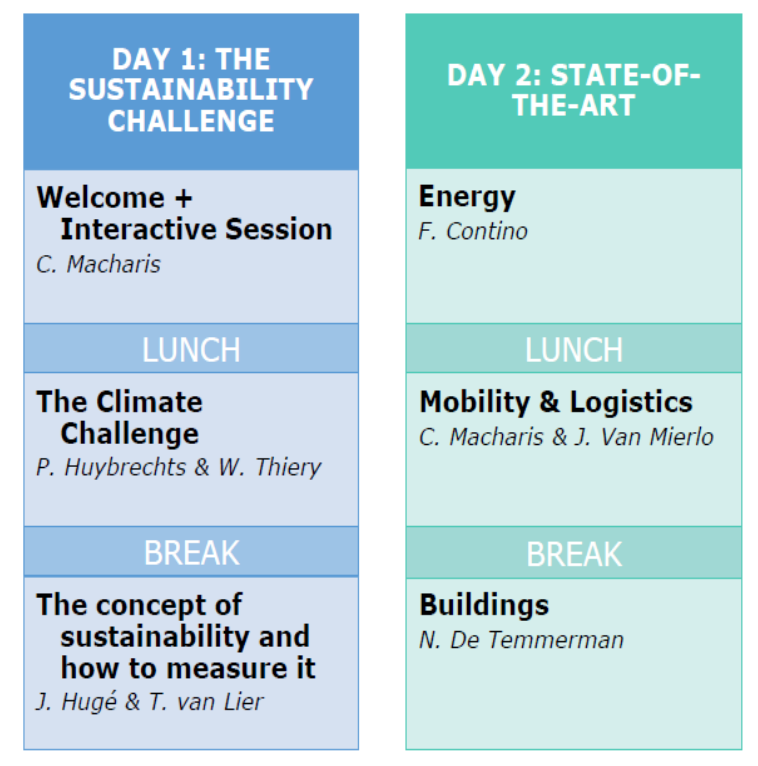

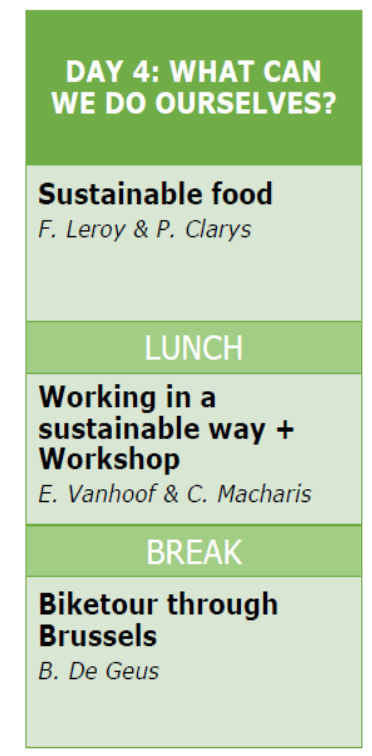

Figure 8. Program Sustainability Bootcamp.

At the end of the bootcamp, an interactive session was organized to ask the participants which advice they would give to companies, governments, and researchers on the one hand, and what they would now change in their life on the other hand. Which change would they make, having heard all the knowledge on the different domains? To determine the answer, we used the G-WAVE method (http:/ / manageable.nl/wp-content/uploads/2015/01/G-Wave.pdf), where the G stands for goal. We asked participants to think about their new goal after the bootcamp. The W stands for the why question or why you would pursue this goal. Then, the actions to be taken to achieve this goal must be listed and then visualized. This visualization often leads to a further refinement of how to prepare for the new behavior. For example, setting the goal to commute by bike to the university once a week because you want to become more sustainable might result in some preparing actions, such as preparing your bike, buying a helmet, and so on. The visualization might make you aware of more aspects that are related to the new behavior, such as having to plan a good and safe route. The E of the G-WAVE acronym stands for engage resources, which might be getting help or support from others. In the example of the bike, it might be the help of a colleague to bike together. This method was found to help with goal commitment and its implementation [24,25].

Additional educational programs in VUB, such as the practical guidance the green team gave on recycling at the VUB restaurant, focused on presenting promising ways to address problems presented by climate change and environmental threats. Thus, the programs were designed to both enhance pathway thinking, showing various ways of feasible solutions to each problem and, at the same time, 
enhancing the agency of the participants, while also enhancing their belief that their actions matter and that they can be a part of the change.

\subsection{Enable}

It is not enough that you know that a problem is urgent and necessary to be solved (estimate), that you feel connected to the problem (engage), and that you know how to solve the problem in an alternative way. The alternative way should be an easy way, maybe even more easy than the traditional way of behaving [5]. Choice architecture should be taken into account when designing university infrastructure [26]. Enabling is truly making it easier to use the sustainable path.

In the VUB initiative, one example is the flight policy at the university. We know from the zero measurement that flights by the academic staff are an important part of the $\mathrm{CO}_{2}$ footprint (see Section 3.1). To start the debate on the topic, we organized a sustainable Tuesday (a yearly event to engage the university community in sustainability issues). The title of the debate in 2017 was "frequent flyer or frequent Skyper". It became clear that there is a willingness to travel less or more by train and to compensate for the flights using a $\mathrm{CO}_{2}$-compensation scheme. However, the message from the academic board was clear: we cannot implement this plan if this will be an extra administrative burden. Indeed, what we are now installing is a centralized purchase policy for travelling. One or two travel agencies will be appointed in a very easy way, and by taking the administrative burden from the researchers, the travels are organized in a sustainable way.

To encourage students to eat more healthily, nudging experiments are being held in the restaurant to nudge students to eat more fruit (by putting out information boards that many others are taking fruit) and less French fries by making the packaging smaller [27].

\subsection{Encourage}

Making change lastly requires encouragement. This can be done by some form of reward or by noticing the change and approving it. The encouragement element in the positive sustainability five $\mathrm{E}$ model was designed to enable participants to increase their belief that they can change their behavior in a more sustainable manner and that their actions matter.

Within the Green Impact program adopted by VUB, encouragement is the key. The aim is to let both staff and students work toward a more sustainable campus. The project was set up as a competition with an award ceremony. Green Impact was a project originally from the British National Union of Students (NUS), but since 2016, it was also held at VUB and coordinated by the VUB Green Team (the Green Team is a team of three students who support the sustainability goals of VUB with concrete actions). In total, the project runs in more than 450 organizations, engaging over 42,000 people, and completing approximately 42,000 actions. In 2017-2018, eight teams competed at VUB, representing 181 colleagues completing 228 actions in total.

This United Nations Educational, Scientific, and Cultural Organization (UNESCO)-awarded program (https://en.unesco.org/greencitizens/stories/green-impact-project) provides a way for bottom-up change by including everyone on campus that wants to make a sustainable change and providing them with the tools to reach their goals. Using social change theory and NUS expertise, the program was developed over the last ten years. The model is made to work in all environments and workplaces year after year. The main themes are continual improvement, collaboration, and meaningful change.

An online toolkit (http://greenimpact.org.uk/vub) specifically tailored for VUB is provided, containing actions one can take to improve sustainability in their office space. The toolkit is packed with examples, but personal input on sustainable ideas is also encouraged and supported through the Green Impact program. Students and staff meet in teams based on the faculty, background, or common areas of work and try completing as many actions as possible, such as changing the settings of the copy machine to let it print in reverse. 


\section{Discussion and Conclusions}

The behavioral change model described in this paper was designed to induce environmental hope to produce a sustainable change in environmental behavior. The various elements of the VUB initiative specifically targeted building trust among different members of the university community by engaging them in dialogue and planning in a collaborative manner. The initiative delineated various paths to achieve sustainability, thus targeting pathway thinking through education practices and dialogue. Finally, the process was designed to raise the agency thinking of the participants by engaging them in designing the process of change and showing them that they were able to take simple actions that will advance sustainability.

The model described in this paper was applied in a university campus and was designed to impact environmental behavior within the framework of the whole-institution approach. The whole-institution approach allows taking into account and integrating the core tasks of a university. At the same time, the 5E model involves all the actors and applies their competences of the four axes of the whole-institution approach together. The estimate phase is something that can easily be incorporated in research, while the educate phase can be implemented within the educational realm, and the enable phase in the operations realm. Engaging and encouraging can be further supported by the outreach realm where external partners can have a motivating factor in reaching the goals. In addition, research should evaluate the impact of the program and later teach it and set as an example through outreach.

Future research should evaluate the impact of this process on the participants' subjective well-being and lasting environmental behavior. Similar programs should be designed and implemented in other campuses so that a cross-sectional study could estimate whether similar programs function differently in diverse contexts.

A further follow-up of the impact of the approach is foreseen by a monitoring of the $\mathrm{CO}_{2}$ carbon footprint reduced thanks to the programs. We also want to have a better view of the participants' perceptions about the different interventions. This was not yet surveyed in a systematic way until now, which is a limitation of this paper. We surveyed the feedback on the bootcamp and the We are Paris campaign, but for the others, we did not have this systematic appraisal. Also, the different stages of the program, as described in the paper, grew organically. This means also that the people that were involved in the different stages changed often. A more systematic combination of the different Es will provide a better set-up that can be assessed in terms of impact. The building blocks as explained in this paper can be applied as described or can serve as an inspiration. At the VUB, the 5E model will now be used to introduce a more sustainable mobility policy in one of the campuses.

The paper describes a first attempt to integrate and implement the whole-university approach to sustainability (Figure 1) with the positive sustainability model. We hope that this paper will encourage other campuses to pursue the positive sustainability approach and apply programs that are likely to impact the environmental footprint of the campus, induce changes in all campus residents, inspire creative solutions to environmental problems, and engage citizens to make the desired changes toward a sustainable future.

Author Contributions: Conceptualization, C.M. and D.K.; resources, C.M. and D.K.; writing-original draft preparation, C.M. and D.K.; writing - review and editing, C.M. and D.K.

Funding: Financial support from the Israeli Science Foundation 584/15 is gratefully acknowledged.

Acknowledgments: The authors would like to thank everyone who was involved in all these actions and especially the people of the core group on Sustainability at VUB. Financial support from the Israeli Science Foundation is gratefully acknowledged.

Conflicts of Interest: The authors declare no conflicts of interest.

\section{References}

1. Keeble, B.R. The Brundtland report: 'Our common future'. Med. War 1988, 4, 17-25. [CrossRef] 
2. John, P. How Far to Nudge?: Assessing Behavioural Public Policy; Edward Elgar Publishing: Cheltenham, UK, 2018.

3. Kollmuss, A.; Agyeman, J.J.E. Mind the gap: Why do people act environmentally and what are the barriers to pro-environmental behavior? Environ. Educ. Res. 2002, 8, 239-260. [CrossRef]

4. Stok, F.M.; Hoffmann, S.; Volkert, D.; Boeing, H.; Ensenauer, R.; Stelmach-Mardas, M.; Kiesswetter, E.; Weber, A.; Rohm, H.; Lien, N.J.; et al. The DONE framework: Creation, evaluation, and updating of an interdisciplinary, dynamic framework 2.0 of determinants of nutrition and eating. PLoS ONE 2017, 12, e0171077. [CrossRef] [PubMed]

5. Steg, L.; Bolderdijk, J.W.; Keizer, K.; Perlaviciute, G. An Integrated framework for encouraging pro-environmental behaviour: The role of values, situational factors and goals. J. Environ. Psychol. 2014, 38, 104-115. [CrossRef]

6. Heath, C.; Heath, D. Switch: How to Change Things When Change Is Hard; Bantam Doubleday Dell Publishing Group: New York, NY, USA, 2010.

7. Gifford, R.J. The dragons of inaction: Psychological barriers that limit climate change mitigation and adaptation. Am. Psychol. 2011, 66, 290-302. [CrossRef] [PubMed]

8. Barth, M.; Michelsen, G.; Sanusi, Z.A. A review on higher education for sustainable development-looking back and moving forward. J. Soc. Sci. 2011, 7, 100-103.

9. Waas, T.; Verbruggen, A.; Wright, T. University research for sustainable development: Definition and characteristics explored. J. Clean. Prod. 2010, 18, 629-636. [CrossRef]

10. Clugston, R.M.; Calder, W. Critical dimensions of sustainability in higher education. Sustain. Univ. Life 1999, 5, 31-46.

11. Mcmillin, J.; Dyball, R. Developing a whole-of-university approach to educating for sustainability: Linking curriculum, research and sustainable campus operations. J. Educ. Sustain. Dev. 2009, 3, 55-64. [CrossRef]

12. Arroyo, P. A new taxonomy for examining the multi-role of campus sustainability assessments in organizational change. J. Clean. Prod. 2017, 140, 1763-1774. [CrossRef]

13. Lozano, R.; Ceulemans, K.; Alonso-Almeida, M.; Huisingh, D.; Lozano, F.J.; Waas, T.; Lambrechts, W.; Lukman, R.; Hugé, J. A review of commitment and implementation of sustainable development in higher education: Results from a worldwide survey. J. Clean. Prod. 2015, 108, 1-18. [CrossRef]

14. Kerret, D.; Orkibi, H.; Ronen, T. Green perspective for a hopeful future: Explaining green schools' contribution to environmental subjective well-being. Rev. Gen. Psychol. 2014, 18, 82-88. [CrossRef]

15. Kerret, D.; Orkibi, H.; Ronen, T. Testing a model linking environmental hope and self-control with students' positive emotions and environmental behavior. J. Environ. Educ. 2016, 47, 307-317. [CrossRef]

16. Helferty, A.; Clarke, A. Student-led campus climate change initiatives in Canada. Int. J. Sustain. High. Educ. 2009, 10, 287-300. [CrossRef]

17. Brinkhurst, M.; Rose, P.; Maurice, G.; Ackerman, J.D. Achieving campus sustainability: Top-down, bottom-up, or neither? Int. J. Sustain. High. Educ. 2011, 12, 338-354. [CrossRef]

18. Astin, A.W.; Astin, H.S. Leadership Reconsidered: Engaging Higher Education in Social Change; ERIC (Education Resources Information Center), 2000. Available online: https:/ / eric.ed.gov/?id=ED444437 (accessed on 2 January 2019).

19. Ockwell, D.; Whitmarsh, L.; O'Neill, S. Reorienting climate change communication for effective mitigation: Forcing people to be green or fostering grass-roots engagement? Sci. Commun. 2009, 30, 305-327. [CrossRef]

20. Corner, A.; Roberts, O.; Chiari, S.; Völler, S.; Mayrhuber, E.S.; Mandl, S.; Monson, K. How do young people engage with climate change? The role of knowledge, values, message framing, and trusted communicators. Wiley Interdiscip. Rev. Clim. Chang. 2015, 6, 523-534. [CrossRef]

21. VUB. The Carbon Footprint of the VUB (2016); VUB: Brussels, Belgium, 2017.

22. Waas, T.; Hugé, J.; Ceulemans, K.; Lambrechts, W.; Vandenabeele, J.; Lozano, R.; Wright, T. Sustainable Higher Education. Understanding and Moving Forward; Flemish Government-Environment, Nature and Energy Department: Brussels, Belgium, 2012.

23. Macharis, C.; De Witte, A.; Turcksin, L. The Multi-Actor Multi-Criteria Analysis (MAMCA) application in the Flemish long-term decision making process on mobility and logistics. Transp. Policy 2010, 17, 303-311. [CrossRef]

24. Stadler, G.; Oettingen, G.; Gollwitzer, P.M. Intervention effects of information and self-regulation on eating fruits and vegetables over two years. Health Psychol. 2010, 29, 274. [CrossRef] [PubMed] 
25. Duckworth, A.L.; Grant, H.; Loew, B.; Oettingen, G.; Gollwitzer, P.M. Self-regulation strategies improve self-discipline in adolescents: Benefits of mental contrasting and implementation intentions. Educ. Psychol. 2011, 31, 17-26. [CrossRef]

26. Thaler, R.H. Nudge: Improving Decisions about Health, Wealth, and Happiness; Yale University Press: New Haven, CT, USA; London, UK, 2008.

27. Deliens, T.; Deforche, B.; Annemans, L.; De Bourdeaudhuij, I.; Clarys, P. Effectiveness of pricing strategies on french fries and fruit purchases among university students: Results from an on-campus restaurant experiment. PLoS ONE 2016, 11, e0165298. [CrossRef] [PubMed]

(C) 2019 by the authors. Licensee MDPI, Basel, Switzerland. This article is an open access article distributed under the terms and conditions of the Creative Commons Attribution (CC BY) license (http:/ / creativecommons.org/licenses/by/4.0/). 